\title{
Tendência histórica da invasão de óbitos em município da Região Sul do Brasil: período de 1936 a 1982
}

\author{
Historical trend in the invasion of deaths in a \\ municipality from Southern Brazil: 1936-1982
}

Milton Roberto Laprega 1

Amábile Rodrigues Xavier Manço 1

\footnotetext{
1 Departamento de Medicina Social, Faculdade de Medicina de Ribeirão Preto, Universidade de São Paulo. Avenida Bandeirantes 3900 Ribeirão Preto, SP 14049-900, Brasil. laprega@netsite.com.br
}

A bstract The authors studied 33,494 deaths occurring in Londrina, State of Paraná, Brazil, from 1936 to 1982 . The deaths were divided into two groups: residents and invaders, who lived outsi de the Londrina municipal limits. Invaders were studied as to origin, place of occurrence, cause, and diagnostic confirmation and compared with residents across proportional mortality. An attempt was made to identify a relationship between invaders' deaths and Londrina's historical development, especially migratory phenomena and health care improvements. Results showed that over the course of the period studied, most of the outsiders who had died in Londrina (over $80 \%$ ) were from northern Paraná. I dentification of the proportion of in-hospital deaths, diagnostic confirmation, and criteria from several chapters of the International Classification of Diseases showed that outsi ders had received proportionally more medical care. Londrina's medical care attracted outsi ders from the beginning of the period onward, a trend that was further consolidated after 1970.

Key words Mortality; Vital Estatistics; Health Statistics; Health Care

Resumo Foram estudados 33.494 óbitos ocorri dos em Londrina, PR, no período de 1936 a 1982. Após a anál ise das alterações nos seus limites territoriais, ocorridas até 1954, os óbi tos foram divididos em resi dentes e invasores. Os invasores foram estudados quanto a sua procedência, local de ocorrência, causa e confi rmação diagnósti ca e comparados com os resi dentes por meio da mortalidade proporcional. Procurou-se rel acionar a invasão de óbitos com o desenvolvimento histórico de Londrina, em particular com os fenômenos mi gratóri os e a evolução da assi stência médica. Verificou-se que em todo o período estudado mais de $82 \%$ dos invasores eram procedentes do Norte do Paraná. O estudo da proporção de óbitos hospitalares, da confirmação diagnóstica e segundo al guns capítulos da CID, em especial os sem assistência médica, demonstrou que os invasores ti veram mais assistência, com Londrina sendo centro de atração em todo o período estudado, posi ção consolidada a partir da década de 70.

Palavras-chave Mortalidade; Estatísticas Vitais; Estatísticas de Saúde; Cui dados de Saúde 


\section{Introdução}

O Norte Novo do Paraná foi colonizado em sua maior extensão pela Companhia de Terras Norte do Paraná, subsidiária da Brazil Plantation Syndicate, de capital inglês, que adquiriu do governo do Estado 515.000 alqueires de terra a partir da década de 1920 (CM NP, 1975).

Em 1930 começaram a ser vendidos os primeiros lotes de terra. A propaganda maciça no NorteVelho do Paraná, São Paulo, Minas Gerais e Rio de Janeiro, as facilidades de aquisição, a fertilidade do solo, o planejamento da divisão das terras, a criação de núcleos populacionais a cada 10 ou $15 \mathrm{~km}$ atraíram para a região grande número de pessoas. Desde então Londrina teve um rápido desenvolvimento com uma economia agrícola baseada na produção de café e culturas intercalares de subsistência (Mombeig, 1935; Cambianghi, 1954; Padis, 1981).

A partir de 1962, devido à superprodução de café em nível mundial, o governo federal adotou uma política de erradicação de cafeeiros (Duque, 1976; Cancian, 1981). Essa alteração provocou mudanças profundas nas relações de produção no campo. Os colonos, expulsos, dirigiram-se às cidades para trabalhar como operários, bóiasfrias, ou viver de pequenos serviços, quando não desempregados (Lopes, 1982; Payes, 1984).

Nos anos 70 essa tendência se intensificou. Acompanhando o processo de "modernização" que ocorreu em nível nacional, implantou-se em quase todo o Norte do Paraná o cultivo da soja e do trigo que, em conjunto com a geada negra de 1975, determinou o fim da cafeicultura e agravou as condições dos pequenos proprietários, que endividados, venderam suas terras e migraram para as cidades ou novas frentes pioneiras como Rondônia e Paraguai (Jornal Panorama, 1975; Padis, 1981; Sawyer, 1984).

Diante deste quadro, algumas questões podem ser levantadas e são objeto de estudo neste trabalho: Londrina, além de centro econômico e político era também um centro de invasão de óbitos? Como evoluiu a invasão de óbitos em Londrina à medida que o município foi se transformando? Em que medida é possível identificar a influência da assistência médicohospitalar no fenômeno da invasão de óbitos e a partir de que momento Londrina tornou-se centro de atração para atendimento à saúde?

\section{Material e métodos}

Até 3 de dezembro de 1934 Londrina foi distrito do Município de Jataí. A partir dessa data, em que se deu sua transformação em municí- pio, sofreu diversas alterações territoriais (1935, 1938, 1939, 1944, 1947, 1952, 1953, 1954), a maioria devido ao desmembramento de novos municípios. Somente a partir de agosto de 1954 adquiriu sua configuração atual. A ocorrência dessa particularidade exi giu a definição do que se considera óbito invasor e da base territorial.

A informação do local de residência de tipo "neste município" foi bastante freqüente no período de definição territorial e não permite identificar se referia-se à sede, aos distritos, ou aos povoados que surgiam e faziam então parte do município. Por outro lado, os nomes dessas localidades foram utilizados com freqüência na informação do local de residência. Para exemplificar, Rolândia, em 1942 fazia parte de Londrina e em 1944 já era um município. Um óbito desse local em 1942 seria de Londrina e em 1944 seria invasor. Uma outra questão que exigiu atenção especial foi o hábito de se informar o local de residência com o nome de glebas, fazendas ou ribeirões.

Para resolver esses problemas reconstituiuse o período histórico de definição territorial por meio de cópias de decretos, mapas antigos, nomes de glebas e loteamentos. De posse dessas informações, optou-se por aceitar na definição da base territorial os limites municipais legalmente constituídos. Todos os casos referidos como dos povoados ou distritos foram considerados de Londrina até o momento de seu desmembramento, a partir de quando foram codificados como invasores.

Os casos que tiveram endereços impossíveis de localizar foram considerados prejudicados e excluídos do estudo e corresponderam em média a $4,1 \%$ dos óbitos registrados no período de 1936 a 1982.

\section{O estudo dos óbitos}

Os óbitos foram levantados de 2 em 2 anos, no período de 1936 a 1982, diretamente das declarações nos dois cartórios da zona urbana de Londrina e dos livros de registros nos oito cartórios distritais.

Os óbitos foram codificados em sistema numérico segundo instruções de um Manual de Codificação, anotados em planilha e encaminhados para processamento eletrônico. Após correção dos erros de codificação e digitação, os dados foram submetidos a testes de consistência, utilizando-se tabela de validade e tabelas de restrição baseadas no Subsistema de Informações em Mortalidade do Ministério da Saúde.

As causas básicas de óbito foram codificadas, utilizando-se a 9a Revisão da Classificação 
Internacional de Doenças (CID-OMS, 1985) e agrupadas segundo os capítulos da CID e de acordo com uma lista de códigos para mortalidade baseada na CID-BR (MS, 1987).

\section{Resultados e discussão}

A maioria dos óbitos invasores vieram da Mesoregião Norte do Paraná (mais de $82 \%$ em todo o período).

Considerando-se o número absoluto de casos, os invasores aumentaram de 14 em 1936 para 827 em 1982 (59 vezes), enquanto os óbitos de residentes aumentaram de 290 para 1686 no mesmo período (5,8 vezes).

Ao se analisar a proporção de óbitos invasores (Tabela 1), pode-se dividir o período em três partes distintas: a primeira, de 1936 a 1948, com tendência crescente; a segunda, de 1948 a 1966, com tendência decrescente; e a terceira, a partir de 1966, com acentuado crescimento.

O aumento dos invasores na década de 40 pode ser explicado pela mudança nos limites territoriais, pois desde janeiro de 1944 todos os óbitos ocorridos de Rolândia para oeste, e a partir do final de 47, os de Cambé, foram classificados como invasores.

Analisando-se os óbitos por local de ocorrência, observa-se uma nítida diferença entre residentes e invasores (Figura 1 ) já a partir de 1940. Nesse ano e em 1942 a proporção de óbitos hospitalares foi de 21,7 e $20,8 \%$, respectivamente, para os invasores, enquanto a de residentes foi de 5,7 e 8,1\%; em 1944 os invasores tiveram uma proporção de $58,6 \%$ e os residentes permaneceram em 9,9\%; em 1946, a proporção foi de $76,5 \%$ para os primeiros e $15,5 \%$ para os segundos e em 1948, 75\% e 10,6\%.

Os óbitos domiciliares foram mais freqüentes para os residentes. Na década de 40 os inva-

Tabela 1

Proporção de óbitos invasores no Município de Londrina, Paraná. Período de 1936 a 1982.

\begin{tabular}{lc}
\hline Anos & Proporção de óbitos invasores (\%) \\
\hline 36 e 38 & 7,7 \\
40 a 48 & 12,0 \\
50 a 58 & 8,7 \\
60 a 68 & 8,2 \\
70 a 78 & 21,8 \\
80 e 82 & 31,6 \\
\hline
\end{tabular}

Figura 1

Proporção de óbitos de residentes e invasores em Londrina, Paraná, segundo local de ocorrência. Período de 1936 a 1982.
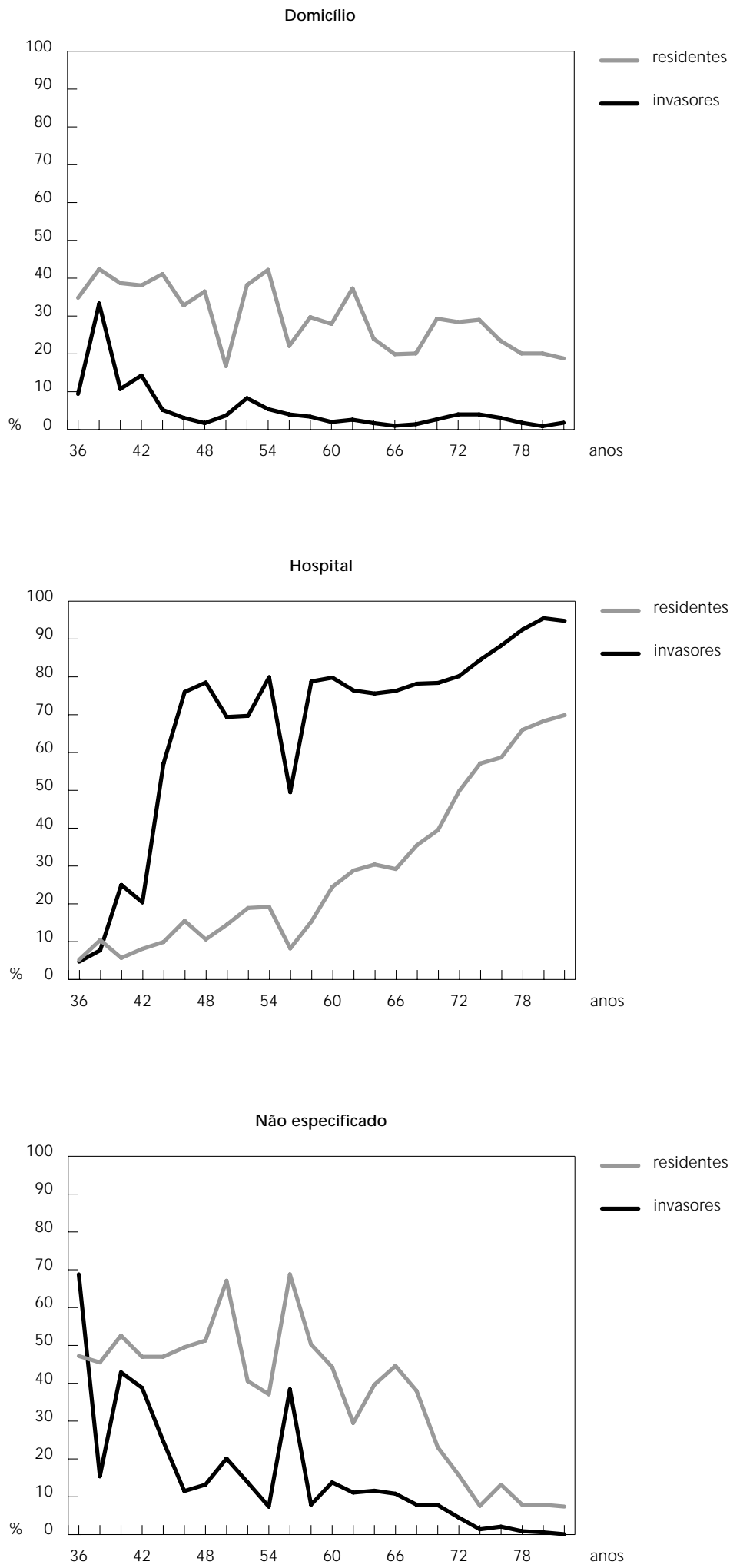
sores tiveram em média $6 \%$ de ocorrência domiciliar e os residentes, $36,4 \%$.

Um outro dado da figura dá consistência a essas observações. A resposta "em Londrina, local não especificado" também teve diferenças acentuadas. Com exceção do ano de 1940 em que os valores são praticamente idênticos entre residentes e invasores e 1942, em todos os outros anos os últimos tiveram essa resposta em proporção bastante menor que os primeiros, o que sugere declarações melhor preenchidas.

Pode-se notar que a proporção de óbitos hospitalares dos invasores sofre um crescimento abrupto entre 1942 e 1944. Como o fenômeno não ocorre com os residentes é pouco provável que essas variações se dêem por modificações na oferta dos serviços de saúde em Londrina.

As alterações dos limites territoriais do município que ocorreram em 1943, desmembrando a maior parte de seu território, podem ser o fator que melhor explique o crescimento dos óbitos hospitalares dos invasores nesse momento.

Os resultados descritos fazem crer que já nos anos 40 Londrina era um centro de atração para assistência médica. As causas de óbito (Figura 2) ajudam a identificar se a ocorrência no município era devido a fatores casuais ou devido à procura de assistência médica.

Os neoplasmas são um bom exemplo: em 1938 foram responsáveis por 2,9\% dos óbitos de invasores e 1,3\% dos residentes, enquanto na década de 40 essas proporções foram em média, 6,1 e 3,2\%, respectivamente.

Como não existem razões para se supor que a população que colonizou Londrina fosse diferente da dos outros municípios da região eos neoplasmas são doenças graves e crônicas, as proporções maiores para os óbitos invasores podem ser explicadas pela procura de assistência médico-hospitalar.

Em 1936 a mortalidade proporcional por causas externas foi $7,1 \%$ para os invasores e $6,6 \%$ para os residentes, havendo uma inversão em 1938, quando os primeiros tiveram 5,7 e os últimos, 8,8\%. Na década de 40, contudo, os invasores tiveram em média proporções mais elevadas, atingindo $7,8 \%$ enquanto os residentes, 5,2\%. Provavelmente esses óbitos incluem casos de pessoas que tiveram morte violenta visitando Londrina e casos graves ocorridos fora e que para lá foram deslocados em busca de assistência médica.

O capítulo XVI, dos Sintomas, Sinais e Afecções Mal Definidas permite concluir esta discussão (OMS, 1985). Nos anos de 36 e 38, prati- camente não houve diferença entre residentes e invasores, mas na década de 40 os primeiros tiveram, em média, uma mortalidade proporcional de $29,6 \%$ enquanto os últimos, 7,9\%.

Analisando-se isoladamente as mortes Sem Assistência Médica, enquanto na década de 30 os residentes alcançaram em média um valor de $27,2 \%$, os invasores chegaram a 32,6\%; já na década de 40 , os valores foram, respectivamente, $26 \%$ e $4,6 \%$ (Tabela 2 ).

Os dados de confirmação diagnóstica não podem ser levados em conta nesse período, uma vez que a declaração vigente não previa a informação e praticamente todos os casos tiveram resposta prejudicada.

Analisando-se os anos de 1950 a 1970 não se pode afirmar que tenha havido uma tendência diferente em relação à freqüência e à taxa de invasão, que permaneceram com valores próximos aos da segunda metade dos anos 40.

Na década de 50 , a frente pioneira já estava no Sudoeste, e no Norte várias cidades cresciam, estruturavam-se e organizavam sua assistência médica. É possível que nesse período, com o crescimento dos serviços de saúde em cada município, tenha havido um certo equilíbrio entre a oferta e demanda e com isso não tenha se alterado em quantidade a invasão de óbitos em Londrina.

A análise dos óbitos por local de ocorrência nesse período revela um crescimento dos hospitalares, tanto para residentes quanto para invasores, mas continua existindo uma diferença acentuada entre eles. Na década de 50, em mé dia $15 \%$ dos residentes morriam nos hospitais e entre os invasores o percentual era de $64,6 \%$. $\mathrm{Na}$ década de 60 esses valores eram, respectivamente, $30,0 \%$ e $82,1 \%$.

Em relação aos óbitos domiciliares os invasores continuaram a ter taxas menores que os residentes. Na década de 50 ocorreram, em média, em $6,4 \%$ dos casos e na década de 60 em $0,8 \%$, enquanto os residentes atingiram em 1950, 29,7\% e em 1960, 25,5\%.

As declarações de óbitos de invasores continuaram melhor preenchidas nesse quesito no período. A informação "Londrina, em local não especificado" apareceu com tendência decrescente, em média, em 53\% das declarações de residentes e $20,2 \%$ dos invasores da década de 50 e em $39,1 \%$ e $10,7 \%$, respectivamente, na década de 60.

As mortes por neoplasmas e causas externas nos invasores superaram as dos residentes e no caso das mal definidas ocorreu o inverso. Diminuíram as mortes sem assistência médica para óbitos invasores, que atingiram valores de $3,7 \%$ nos anos 50 e $1,6 \%$ nos anos 60 . Os valo- 
res para os residentes permaneceram estáveis, com $27,3 \%$ na década de 50 e $28,9 \%$ na de 60 .

A análise da confirmação diagnóstica (Tabela 3) mostra que embora tenha havido um aumento no preenchimento dessa informação para invasores e residentes, os primeiros apresentaram proporções maiores em todo o período.

Concluindo, é possível afirmar que entre os anos de 1950 e 1970, apesar de não existir aumento importante na quantidade e na proporção de óbitos invasores, aumentou a proporção de óbitos com assistência médica e Londrina continuou a ser um centro de atração.

A partir de 1970 há um crescimento acentuado em número e proporção de invasores, enquanto os óbitos de residentes permanecem estáveis. Os invasores continuam a morrer proporcionalmente mais nos hospitais, 96,9\% em 1980, enquanto os residentes atingem 69,9\% em 1982. A resposta “Londrina, em local não especificado" cai a praticamente zero para os invasores em 1982 e a 7,4\% para os residentes.

As Afecções Mal Definidas tem uma diminuição acentuada nos dois grupos e em particular com relação aos óbitos Sem Assistência Médica, que variam de 22,2\% em 1970 para 2,4\% em 1980 para os residentes, enquanto os invasores que tinham $0,6 \%$ em 70 , terminam o período estudado sem apresentar nenhum caso nos dois últimos anos.

A confirmação diagnóstica variou de 32,4\% em 1970 para 72,5\% em 1980 entre os invasores e de $8,7 \%$ para $60,7 \%$ entre os residentes.

Pela análise dos dados desde o ano de 1936 é possível concluir que foi a partir de 1970 que houve o maior crescimento da proporção de óbitos invasores e a mais acentuada influência da assistência médica. Conforme períodos anteriores, os óbitos invasores detêm os índices mais altos de ocorrência hospitalar e confirmação diagnóstica e os menores de Afecções Mal Definidas e Sem Assistência Médica.

O nítido crescimento das proporções de invasão pode, nesse período, ser explicado por um rápido e importante desenvolvimento da assistência médica no município. Após a criação da Faculdade de Medicina em 1966, na década de 70 foram instaladas várias clínicas, hospitais e fixaram-se muitos médicos na cidade, que aumentaram a oferta de serviços em número e em complexidade, consolidando Londrina como pólo de atração regional. É necessário, contudo, que se faça um estudo da evolução da assistência médica em Londrina, para se estabelecer de forma direta essa relação.

\section{Figura 2}

Mortalidade proporcional segundo alguns capítulos da CID. Comparação entre óbitos de residentes e invasores. Londrina, Paraná, período de 1936 a 1982.

Capítulo II

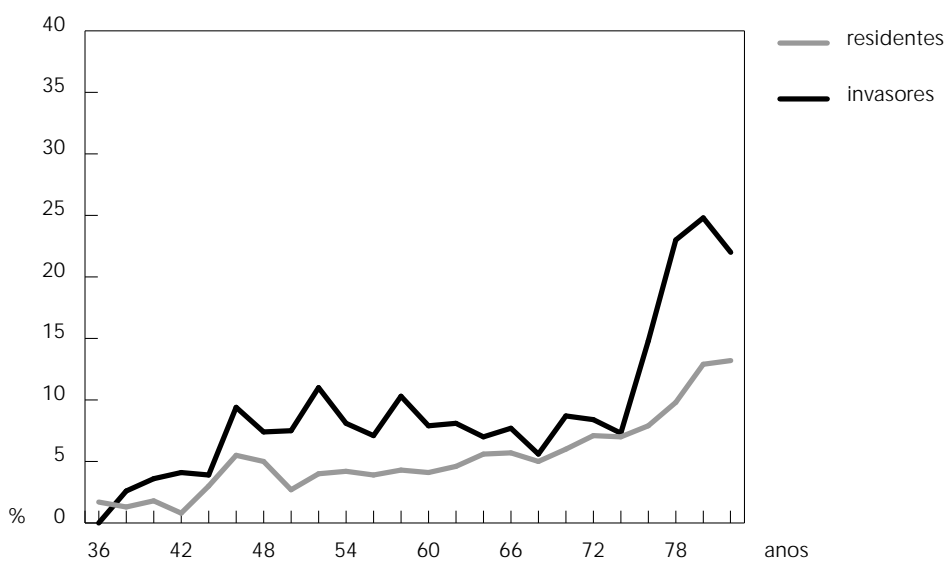

Capítulo XVI
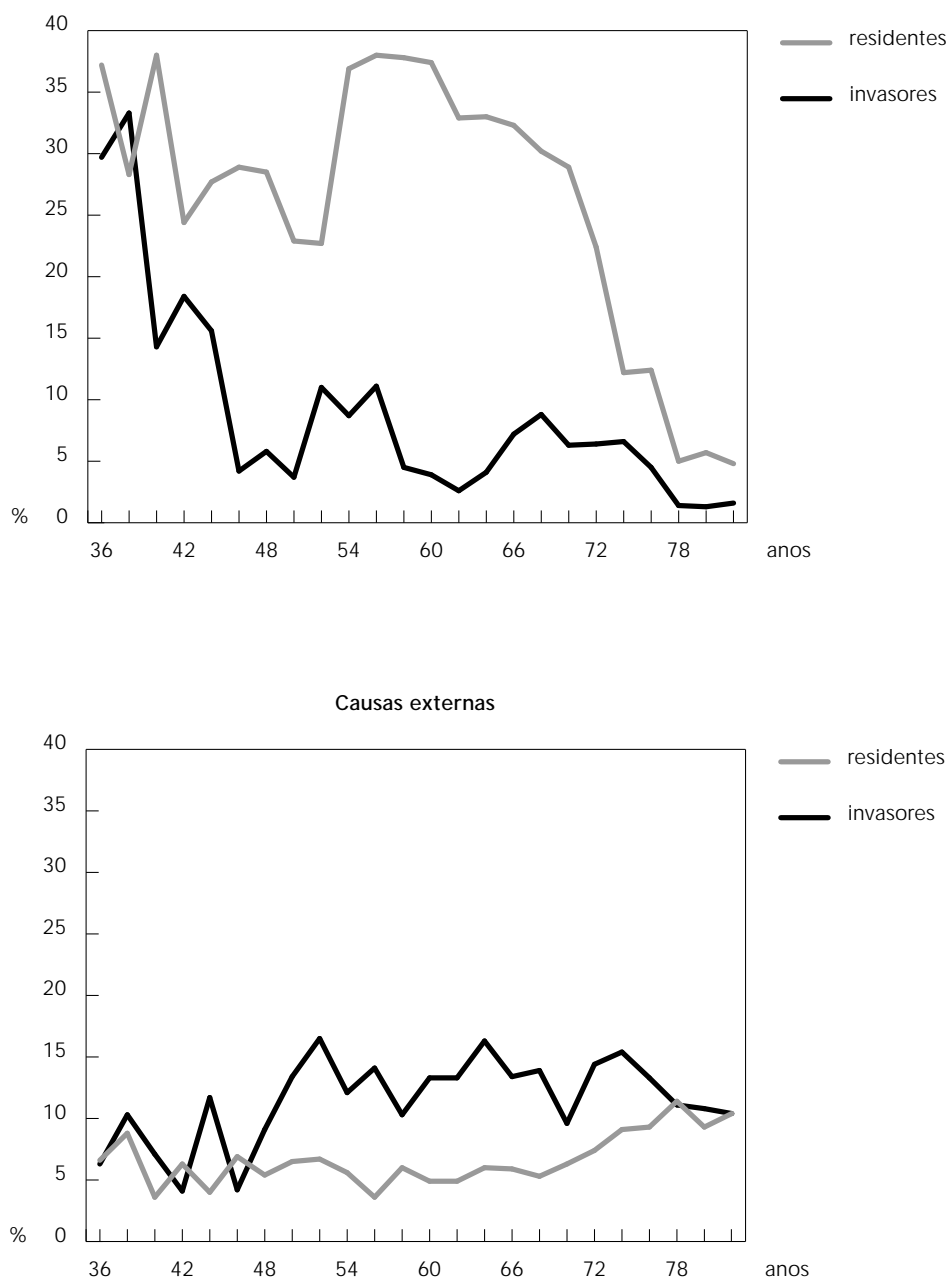
Tabela 2

Ó bitos sem assistência médica no Município

de Londrina, Paraná, no período de 1936 a 1982.

Comparação entre residentes e invasores.

\begin{tabular}{|c|c|c|}
\hline Ano & Residentes & Invasores \\
\hline 36 & 34,5 & 35,7 \\
\hline 38 & 20,0 & 31,4 \\
\hline 40 & 35,5 & 13,0 \\
\hline 42 & 19,4 & 20,8 \\
\hline 44 & 24,0 & 2,9 \\
\hline 46 & 25,2 & 3,5 \\
\hline 48 & 23,8 & 1,0 \\
\hline 50 & 18,0 & 0,8 \\
\hline 52 & 18,4 & 4,5 \\
\hline 54 & 32,6 & 6,1 \\
\hline 56 & 31,5 & 1,4 \\
\hline 58 & 29,7 & 8,2 \\
\hline 60 & 34,3 & 0,7 \\
\hline 62 & 34,0 & 3,0 \\
\hline 64 & 31,1 & 2,5 \\
\hline 66 & 28,8 & 1,1 \\
\hline 68 & 24,4 & 0 \\
\hline 70 & 22,2 & 0,6 \\
\hline 72 & 14,0 & 0 \\
\hline 74 & 4,8 & 0,6 \\
\hline 76 & 4,7 & 0,6 \\
\hline 78 & 3,5 & 0,1 \\
\hline 80 & 2,7 & 0 \\
\hline 82 & 2,4 & 0 \\
\hline
\end{tabular}

\section{Conclusões}

Após a compra de $1 / 16$ do território paranaense, a Companhia de Terras Norte do Paraná elaborou um projeto de colonização que atraiu para a região milhares de pessoas.

Junto com os camponeses, nos núcleos urbanos instalou-se uma estrutura de serviços. A própria Companhia de Terras Norte do Paraná construiu em 1930 um hotel que mais tarde transformou-se no "Hospitalzinho de Indigentes".

Com os comerciantes vieram os médicos. Seguiam o rastro da frente pioneira, montavam suas clínicas, adaptavam casas de madeira para fazer internações.

Londrina, porta de entrada e retaguarda do processo de colonização, sede da Companhia de Terras, estruturou-se primeiro e tornou-se desde o início um centro de atração para assistência médica. E se à medida que a frente pioneira avançava os novos núcleos de colonização ganhavam seus médicos, a assistência mé-
Tabela 3

Confirmação diagnóstica dos óbitos registrados

em Londrina, Paraná, no período de 1950 a 1982.

Comparação entre residentes e invasores. Porcentagens.

\begin{tabular}{lrr}
\hline Ano & Residentes & Invasores \\
\hline 50 & 3,8 & 13,5 \\
52 & 2,1 & 10,1 \\
54 & 2,8 & 2,4 \\
56 & 1,2 & 5,5 \\
58 & 4,5 & 17,8 \\
60 & 3,1 & 9,8 \\
62 & 6,3 & 26,7 \\
64 & 6,4 & 27,4 \\
66 & 4,7 & 29,6 \\
68 & 8,7 & 24,9 \\
70 & 8,7 & 32,4 \\
72 & 21,8 & 42,7 \\
74 & 19,6 & 32,8 \\
76 & 24,8 & 37,4 \\
78 & 46,9 & 67,8 \\
80 & 50,9 & 70,0 \\
82 & 70,7 & 72,5 \\
\hline
\end{tabular}

dica em Londrina melhorava seus recursos. $\mathrm{Na}$ década de 40 foi fundada a Santa Casa, nos anos 50 a Casa de Saúde do Dr. Jonas, nos anos 60 o Hospital Evangélico e o Sanatório de Tuberculose e na década de 60 foi fundada a Faculdade de Medicina.

A estruturação da assistência médica seguiu o movimento da frente pioneira, atingindo progressivamente pontos mais avançados, ao mesmo tempo em que ocorreu uma concentração de equipamentos e recursos humanos no $\mathrm{Mu}$ nicípio de Londrina, projetado para ser a porta de entrada e o centro de gravidade do projeto de colonização do Norte Novo do Paraná.

Essa característica especial da história de Londrina garantiu o investimento do capital necessário para incentivar a migração, a ocupação do solo e o início da produção. Não é por acaso que lá chegaram primeiro a ferrovia, as linhas telefônicas, que a própria Companhia de Terras se encarregou de instalar o primeiro hospital.

Os dados de local de ocorrência, mortalidade por causas, óbitos sem assistência médica e confirmação diagnóstica revelam diferença nítida entre invasores e residentes e são suficientes para afirmar que a população da região procurava o município para obter a assistência médica que não encontrava em seu local de moradia. 


\section{Referências}

CAMBIANGHI, S. M., 1954. O povoamento do norte do Paraná. Anais da Associação dos Geógrafos Brasileiros, 6:81-90.

CANCIAN, N. A., 1981. Cafeicultura Paranaense 1900/1970. Curitiba: Grafipar.

CM NP (Companhia Melhoramentos Norte do Paraná), 1975. Colonização e Desenvolvimento do Norte do Paraná. Publicação Comemorativa do Cinqüentenário da Companhia Melhoramentos Norte do Paraná. São Paulo: CMNP.

DUQUE, H. M., 1976. A Luta pela Modernização da Economia Cafeeira: Assim Agem as Multinacionais. São Paulo: Editora Alfa Omega.

GOMES, A. M., 1938. Álbum do Município de Londrina. Londrina: s.n.

JORNAL PANORAMA, 1975. Londrina: Edição histórica. Jornal Panorama, Londrina, 9 mar., Caderno “Economia", pp. 5-61.

LOPES, A. Y. D. P., 1982. Pioneiros do Capital: a colonização do Norte Novo do Paraná. Dissertação de Mestrado, São Paulo: Faculdade de Filosofia, Letras e Ciências Humanas, Universidade de São Paulo.

MOMBEIG, P., 1935. A zona pioneira do norte do Paraná. Geografia. Associação dos Geógrafos Brasileiros, 3:221-236.
MS (Ministério da Saúde), 1987. Lista Brasileira para Mortalidade. Brasília: Centro de Documentação do Ministério da Saúde.

NAKAGAWARA, Y., 1982. Evolução e Distribuição da População Paranaense. Paraná, Mundo Rural. Londrina: Departamento de Geociências, Fundação Universidade Estadual de Londrina. (mimeo.)

OMS (Organização Mundial da Saúde), 1985. Manual da Classificação Estatística Internacional de Doenças, Lesões e Causas de Óbito. 9a Revisão. São Paulo: Centro Brasileiro para Classificação de Doenças.

PADIS, P. C., 1981. Formação de uma Economia Periférica: O Caso do Paraná. São Paulo: Editora Hucitec.

PAYES, M. A. M., 1984. O Norte do Paraná: Expansão Cafeei ra eApropriação da Renda Fundiária desde Fins do Século XIX até 1960. Dissertação de Mestrado, Itaguaí: Instituto de Ciências Humanas e Sociais, Universidade Federal Rural do Rio de Janeiro.

SAWYER, D. R., 1984. Fluxo e refluxo da fronteira agrícola no Brasil: Ensaio de interpretação estrutural e espacial. Revista Brasileira de Estudos de População, 1:3-34. 